\title{
EL CONCEPTO DE VIOLENCIA EN EL PENSAMIENTO POLÍTICO REVOLUCIONARIO
}

\section{THE CONCEPT OF VIOLENCE IN REVOLUTIONARY POLITICAL THOUGHT}

\author{
Jorge Zeledón S. \\ Universidad Estatal a Distancia de Costa Rica \\ Javier Jiménez A. \\ Universidad Nacional de Costa Rica
}

Recibido: 6 de agosto, 2015 • Aceptado: 21 de setiembre, 2015

Resumen: En el presente escrito se analiza el tema de la violencia revolucionaria desde la perspectiva estructural y situacional en el pensamiento de Karl Marx, Federico Engels, Vladimir Lenin y George Sorel. La violencia revolucionaria en la concepción de estos pensadores constituye un recurso legítimo de liberación en las sociedades de clases y expresa la reacción a la violencia derivada de la dominación burguesa. En concreto se examinan las obras clásicas de los autores referidos, estas son el Manifiesto del Partido Comunista, El Estado y la revolución y Reflexiones sobre la violencia.

Palabras clave: violencia, lucha de clases, Estado, proletariado, sistema de dominación, moral

\begin{abstract}
In writing the theme of revolutionary violence is analyzed from the structural and situational perspective on the thought of Karl Marx, Frederick Engels, V. Lenin and George Sorel. Revolutionary violence in the conception of the authors constitutes a legitimate source of liberation in class societies and expresses the reaction to violence due to bourgeois rule. Classics of those authors, The Communist Manifesto, The State and Revolution, Reflections on violence are examined.
\end{abstract}

Keywords: Violence, Class Struggle, Estate, Proletariat, State Imperial Domination System, Morality 


\section{La violencia revolucionaria del proletariado: Marx y Engels y El mani- fiesto comunista}

Para discernir el papel que adquiere la violencia revolucionaria contenida en el Manifiesto del Partido Comunista (1848), tanto en su carácter estructural como situacional, es imprescindible tener como referente la idea de la lucha de clases, pero a la vez esta no se puede comprender debidamente si no es a partir de los supuestos teóricos y metodológicos que el materialismo histórico otorga al análisis de las formaciones económico-sociales concretas, superando la lectura puramente economicista de la misma, como podría seguirse de una lectura de la letra de ciertos textos del Manifiesto del Partido Comunista. El filósofo-académico Helio Gallardo (1989) sugirió que, metodológicamente, la noción de lucha de clases exige ser pensada desde la categoría de formación económico-social, una entidad diferenciada, articulada y compleja, y no desde el reducido movimiento económico ligado al conflicto entre el desarrollo de las fuerzas productivas y las relaciones de producción. Estas premisas se articularían alrededor de los siguientes enunciados: a) El proceso de producción debe ser estudiado a partir de la producción inmediata de las condiciones de vida que necesariamente los hombres tienen que reproducir; b) el intercambio que caracteriza al modo de producción capitalista, cuya materialización es la sociedad civil, constituye el fundamento de toda historia. Históricamente, este fundamento se presenta bajo la forma del Estado. La acción de este último determina los diversos productos teóricos y las formas que adquiere la conciencia: la religión, la filosofía, la moral; c) se concibe las formaciones ideológicas sobre la base de la práctica material. Lo anterior significa que los productos de la conciencia no pueden ser destruidos mediante la crítica espiritual, esto solo podrá lograrse cuando desaparezcan las relaciones sociales reales que las producen; d) que las fuerzas motoras de la historia, al contrario de lo que generalmente se supone, no son ni la religión, ni la filosofía ni la crítica, sino la revolución; e) cada fase de la historia es el resultado natural de la actitud de los hombres hacia la naturaleza y de los unos hacia los otros; esta actitud se trasmite de una generación a otra y condiciona su desarrollo; y f) las fuerzas productivas y las relaciones de producción con las cuales cada individuo y cada generación se encuentra son asumidas históricamente 
como lo dado. De lo anterior se concluye que los filósofos al moverse en un plano abstracto confunden lo real-social (fuerzas productivas, relaciones de producción) con la denominada esencia del hombre, elevándola a la categoría de autoconciencia.

La concepción materialista de la historia entiende lo real-social como un proceso complejo, en el cual las fuerzas productivas y las relaciones sociales inevitablemente entran en contradicción al no poder resolverse el conflicto capital-trabajo, lo que estructuralmente condiciona el carácter violento que asume el enfrentamiento entre las clases antagónicas en el modo de producción capitalista. Consecuentemente, para Marx es la lucha de clases la que explica el surgimiento del Estado, cuyo papel principal es posibilitar la reproducción de la dominación de clase. Así, es el conflicto estructural referido el que permite entender el sentido y las formas que adquiere la violencia en un contexto de lucha de clases.

En el capitalismo el Estado (máquina de la dominación) hace aparecer la violencia estructural como un orden natural de la sociedad. Junto a la violencia estructural también es posible distinguir la violencia situacional, que se manifiesta como formas de intervenciones directas, tal es el caso de las guerras y del castigo físico, con el propósito de conseguir la modificación de una conducta. Este mecanismo de la violencia física como castigo es sumamente efectivo, pues opera sobre la base de que la vida y la integridad física es un valor o un bien muy preciado por todos los individuos.

Como respuesta a la violencia legítima de la dominación burguesa se produce la violencia revolucionaria, caracterizada por Carlos Marx (18181883) y Federico Engels (1820 - 1895) como una ley de la historia (partera de la historia). La violencia revolucionaria no es necesariamente armada, aunque sí contestaria respecto de la violencia estructural. En este sentido, es liberadora y potenciadora del ser humano. En el nivel situacional la violencia revolucionaria se manifiesta en enfrentamientos armados, huelgas y diversos tipos de resistencia popular.

En el Manifiesto del Partido Comunista los autores desentrañaron el papel de partera que juega la historia, asumida como el espacio y el proceso histórico mediante el cual la burguesía y el proletariado se configuran como las dos fuerzas que luchan, una por mantener y la otra por destruir el orden burgués dominante. 
«La historia de todas las sociedades hasta nuestros días es la historia de la lucha de clases» (Marx y Engels, 1978, p. 111). Esta idea, la idea de la lucha de clases, es central en la comprensión del Manifiesto del Partido Comunista y para entender el carácter de la violencia revolucionaria, pues, como bien afirma Chevallier en Los grandes textos políticos (1974), este concepto enmarca la historia en un espacio cuya característica es el enfrentamiento entre clases. En palabras de Engels:

Toda la historia ha sido una historia de la lucha de clases, de lucha entre clases explotadas y clases explotadoras, entre clases dirigidas y clases dirigentes en los diferentes estadios de la evolución social, pero que esta lucha ha llegado en la actualidad a una fase en que la clase explotada y oprimida (el proletariado) no puede ya liberarse de la clase que la explota y oprime (la burguesía) sin liberar al mismo tiempo y para siempre a la sociedad entera de la explotación, de la opresión y de las lucha de clases (Chevallier,1967p. 273).

La lucha de clases se expresa como pugna en torno a la apropiación privada de la riqueza socialmente producida, y es, por lo tanto, el principio de la propiedad privada, lo que explica la división social y las luchas que se generan por obtener y conservar el poder. El análisis de Marx permite comprender la dialéctica del papel desempeñado por estas luchas, que han colocado frente a frente a la burguesía y al proletariado en el modo de producción capitalista.

Entonces, la burguesía, cuyo origen se encuentra en la disolución de la clase feudal, no resolvió el conflicto estructural de la sociedad; más bien sustituyó los antiguos métodos de lucha, simplificándolo a la oposición de dos clases (burguesía y proletariado). La burguesía fue valorada por Marx como una clase que vino a revolucionar toda la estructura de la vieja sociedad y puso fin a la concepción idílica que, sobre la actividad humana, poseía el feudalismo y reveló las relaciones entre los hombres en sus verdaderos términos mercantiles.

Sobre esta última idea es quizás importante recordar que el cálculo egoísta que Marx reconoció en la burguesía es precisamente uno de los puntos de partida del análisis antropológico realizado por Hobbes (1994) que le permitió justificar el surgimiento del Estado absoluto como la única instancia capaz de dirimir los conflictos entre los hombres. 
En cuanto a la condición de clase explotadora que se le reconoce a la burguesía, es igualmente importante afirmar que el concepto marxista de clase contiene o remite al concepto de explotación. En la sociedad capitalista, mediante el mecanismo del salario, todas las relaciones humanas quedan reducidas a simples transacciones o relaciones económicas de explotación de una clase sobre otra.

En el Manifiesto del Partido Comunista se asigna un carácter inevitablemente revolucionario a la burguesía, como nueva clase social dominante, el cual es explicado como un proceso dialéctico, como etapa histórica necesaria. Pero, asimismo, en el seno de esta clase se gestaron las condiciones para el desarrollo de su antítesis, el proletariado, que fue la clase destinada a destruir mediante un enfrentamiento abierto a la burguesía. No fue, pues, desde un reducido y mecánico movimiento económico ligado al conflicto entre el desarrollo de las fuerzas productivas y las relaciones de producción que se gestaron los cambios revolucionarios. Esta tesis o interpretación economicista resta importancia al papel de la violencia, en el período de transición de un orden de producción a otro. Por el contrario, el proletariado, en cuanto encarnó su papel de clase revolucionaria, tuvo que cambiar las condiciones histórico-sociales que lo determinaban como tal y que lo condenaban a ser una clase explotada, y esto último no fue posible sino mediante el empleo de la violencia:

Al esbozar las fases más generales del desarrollo del proletariado, hemos seguido el curso de la guerra civil más o menos oculta, que se desarrolla en el seno de la sociedad existente, hasta el momento en que se trasforma en revolución abierta y el proletariado derrocando por la violencia a la burguesía, implanta su dominación (Marx y Engels, 1978a, p. 121).

Marx entendía el poder político burgués como violencia organizada. Esa violencia derivada de las nuevas condiciones económicas permite articular el concepto de violencia con el de economía. Para fundamentar lo anterior podríamos acudir a la ilustración que, de estos aspectos, introdujo Engels en su polémica con Duhring:

Que el poder no es un mero acto de voluntarismo exige para su actuación previas condiciones reales, señaladamente herramientas o instrumentos, la 
más perfecta de las cuales supera a la menos perfecta, y que además es necesario haber producido esas herramientas, con lo que queda al mismo tiempo dicho que el productor de herramientas de poder más perfectas... vence al productor de las menos perfectas, o sea, en una palabra, que la victoria del poder o la violencia se basa en la producción de armas, y estas a su vez en la producción en general, es decir: en el poder económico, en la situación económica, en los medios materiales a disposición de la violencia (Engels, 1978b, p. 296).

De lo anterior se sigue que la clase que alcance el dominio de la producción material, alcanza a su vez el monopolio de la producción de los instrumentos que permiten el uso de la violencia organizada. La lucha con el proletariado se torna más aguda en la medida en que las fuerzas productivas, desatadas por la burguesía, frenan las nuevas relaciones de producción; de esa tensión surge el enfrentamiento y el carácter violento que adquiere la lucha de clases: «En los períodos en que la lucha de clases se acerca a su desenlace, el proceso de desintegración de la clase dominante, de toda la vieja sociedad adquiere un carácter tan violento y tan agudo...» (Marx y Engels, 1978a, p. 120).

En esa última etapa de la lucha, declararon Marx y Engels, «los comunistas proclaman abiertamente que sus objetivos solo pueden ser alcanzados derrocando por la violencia todo el orden social existente» (1978a, p. 140).

A modo de conclusión, podemos destacar que el mismo Marx dio cuenta de su aporte en los términos siguientes:

Lo nuevo que yo he hecho es haber demostrado: 1)- que la existencia de las clases solo se refiere a ciertas batallas históricas de desarrollo de la producción; 2)- que la lucha de clases conduce necesariamente a la dictadura del proletariado; 3) que esta misma dictadura no es más que la transición a la supresión de todas las clases y a la sociedad sin clases (Chevallier, 1974, p. 289).

\section{Vladimir I. Lenin: el Estado como máquina de dominación}

Vladimir Lenin (1870-1924) caracterizó la violencia como un recurso del Estado burgués, y en cuanto instrumento de la dominación de clase definió este Estado como: «Una Institución que subordina el poder de las 
masas al poder de una minoría armada y organizada» (Lenin, 1979, p. 8). Y apoyándose en las tesis marxistas subrayó el carácter histórico del Estado:

El Estado es producto y manifestación de la irreconciabilidad de las contradicciones de clase. El Estado surge en el sitio, en el momento y en la medida en que las contradicciones de clase no pueden objetivamente conciliarse y viceversa: La existencia del Estado demuestra que las contradicciones de clase son irreconciliables (p. 8).

En sus análisis sobre el papel de Estado, Marx caracterizó a este como órgano de opresión de una clase por otra. El Estado es la creación del «orden» que legaliza y afianza la opresión amortiguando los choques entre las clases.

Las consideraciones anteriores las encontramos también en el pensamiento político de Ernesto Guevara, quien, al definir el carácter del Estado en América Latina como un instrumento del sistema imperial de dominación, consideraba que, dadas las condiciones históricas —en América latina-, tanto las vías de la revolución como el asalto al poder revestirían igualmente un carácter sumamente violento. La otra opción, según Guevara, es llegar a capturar la superestructura, es decir, ganar por vía electoral la administración del aparato burocrático, que, como muy bien sabemos hoy, ha significado invariablemente derrotas políticas para los movimientos populares. Los casos de Chile, Nicaragua y Haití son claros ejemplos de lo anterior y de alguna manera refuerzan la aguda percepción que a ese respecto tenía Ernesto Guevara:

"Lo más que se lograría sería la captura formal de la superestructura burguesa del poder y el tránsito al socialismo de aquel gobierno que, en las condiciones de la legalidad burguesa establecida llega al poder formal, deberá hacerse también en medio de una lucha violentísima contra todos los que traten, de una manera u otra, de liquidar su avance hacia nuevas estructuras sociales (Guevara, 1977b, p. 229). “

Sin absolutizar ningún camino, Guevara concluyó que «frente a la decisión de alcanzar sistemas sociales más justos en América debe pensarse fundamentalmente en la lucha armada. Existe sin embargo, alguna posibilidad de tránsito pacífico...» (p. 229). 
Sobre lo anterior, es importante señalar que quienes han denotado el pensamiento político de Guevara generalmente lo han presentado como un líder que avalaba ciegamente el empleo de la violencia como recurso absoluto de la estrategia revolucionaria. Sin embargo, con relación al papel de la violencia, es importante recordar que Guevara se limitó a expresar con lucidez los principios doctrinarios de Marx y Engels, quienes sostenían que toda revolución es inevitablemente violenta. El mismo Lenin afirmó en su momento que «la sustitución del Estado burgués por el Estado proletario es imposible sin una revolución violenta» (Lenin, 1979, p. 7). Es el carácter estructuralmente violento que adquiere la dominación en las sociedades de clase la razón que explica las limitaciones estratégicas que luego Guevara encontró a las llamadas «vías pacíficas de la revolución» en América Latina.

Lenin enseñó en El Estado y la revolución (1979) que los pueblos necesitan, de modo transitorio, del Estado, puesto que necesitan emplear ese poder contra el sistema de dominación, pero, en un segundo momento, con la toma del poder formal, el proletariado, en tanto clase, se destruye a sí mismo, acto mediante el cual se libera al conjunto de la sociedad. El Estado se constituye así, de un modo dialéctico, en medio y fin para el proletariado. En cuanto medio, se requiere de su fuerza para lograr su propia aniquilación. En tanto fin, marca el punto de ruptura entre la prehistoria (las sociedades de clase) y la historia (sociedad comunista), en la cual será por primera vez posible hablar de un sujeto humano, cuyas relaciones serán trasparentes y ricamente determinadas, puesto que habrá finalizado el reino de enajenación y fetichización que mantenía a los hombres en un continuo desgarramiento y condenados, como Sísifo, a empujar su falsa existencia, la cual solo vivían como auto aniquilamiento por parte de un sistema cuya reproducción material supone, como premisa, la no realización de los hombres. Sistema que, curiosamente, abre y cierra, en un mismo movimiento, la posibilidad de un mundo en el cual los hombres podrán al fin apropiarse de las condiciones histórico-sociales que los producen como tales.

El rostro devastador y deshumanizante que hoy muestra el capitalismo, en especial con su idea del mercado autorregulado (FJ. Hinkelammert), otorga gran vitalidad a muchas de las tesis que los fundadores del materialismo histórico postularon en torno al tema de la destructibilidad ineluctable del 
capitalismo; tema que retomó Lenin en su obra, como arma en su lucha por reivindicar el contenido del paradigma revolucionario.

\section{La apología de la violencia proletaria: Sorel y el sindicalismo revolucionario}

La repulsa a las tácticas del socialismo parlamentario y a las influencias positivistas sobre el pensamiento marxista llevó a Georges Sorel (18471922) a formular un enérgico llamado a la acción, expresada en la violencia proletaria de la huelga general. La influencia bergsoniana sobre el pensamiento de Sorel se hizo evidente al insistir este en las virtudes de la acción violenta en sí misma, como medio para evitar el reblandecimiento ya no solo del proletariado y su misión histórica de sujeto revolucionario, sino de la misma burguesía, a la cual solo la imposibilidad de llegar a compromisos con el primero la obligó a llevar sus potencialidades como clase social hasta las últimas consecuencias.

El famoso elan vital bergsoniano se hace presente aquí, al exteriorizarse la fuerza moral de la voluntad de los sujetos, como intersubjetividad actuante frente al determinismo propio de las concepciones positivistas de Comte y Spencer, para los cuales todo el universo social se rige por leyes inmutables. La violencia como expresión de una voluntad colectiva, de acuerdo con Gramsci, constituye, en sí misma, la fuerza de un mito capaz de movilizar a quienes se enfrentan a la violencia de las clases dominantes; de ahí la necesidad de realizar una apología de la violencia, que en el discurso soreliano debe, casi siempre, ser interpretada como violencia ideológica, vinculada a los actos de rebelión. Al respecto afirmó: «Hoy no vacilo en declarar que el socialismo no podría subsistir sin una apología de la violencia» (Sorel, 1973, p. 207).

El análisis soreliano parte de las premisas siguientes: a)- La violencia expresa una necesidad histórica; b)- existe una moralidad en la violencia; c)- la violencia de la huelga general juega un papel decisivo como medio para la transformación profunda de las sociedades; y d)- la violencia expresada en la idea-mito de la huelga general constituye la base de la nueva moral: la de los productores. 


\section{La violencia como necesidad histórica}

Sorel, apoyado en la tesis expresada por Marx y Engels en el Manifiesto del Partido Comunista, sostuvo que: a)- El capitalismo en virtud de ciertas leyes preavisa el mundo futuro; b) - el fin del capitalismo es obra de la acción del proletariado; c) - el capitalismo crea las condiciones y los medios de su propia destrucción; y d) - las nuevas formas que adquiere el trabajo empujan a los obreros a la rebelión. Literalmente afirmó:

Cabría pues decir que el capitalismo juega un papel análogo al que Hartmann atribuye a lo inconsciente en la naturaleza, ya que prepara la llegada de formas sociales que no intenta producir. Sin plan de conjunto, sin ninguna idea directriz, sin idea de un mundo futuro, determina una evolución perfectamente segura, saca del presente todo lo que puede ofrecer para el desarrollo histórico, hace todo lo preciso para que una nueva era pueda aparecer, de manera casi mecánica y que pueda romper todo vínculo con la ideología de los tiempos actuales, a pesar de la conservación de las adquisiciones de la economía capitalista (Sorel, 1973, p. 84).

Estas palabras muestran con claridad la lectura y posición radicalmente revolucionaria del pensamiento político de Sorel, quien, al definir la necesidad históricamente revolucionaria de la violencia proletaria, intentó poner freno a las posiciones del llamado «socialismo parlamentario», para las cuales las transiciones obedecen a fenómenos superestructurales, totalmente ajenos a la voluntad de los sujetos históricos. Para él «los socialistas deben dejar de buscar (a remolque de los utopistas) los medios de llevar a la burguesía ilustrada a preparar el paso a un derecho superior, su única función consiste en ocuparse del proletariado para explicarle la grandeza del papel revolucionario que le incumbe» (Sorel, 1973, p.85)

Es claro que Sorel percibió la necesidad de la violencia en función del papel revolucionario que le atribuyó al proletariado. Desde esa perspectiva, pensó la violencia desde el espacio definido por la lucha de clases: «Que nadie conserve ilusiones acerca del carácter de las violencias. Las cuales no pueden tener valor histórico más que si son la expresión brutal y clara de la lucha de clases» (Sorel, 1973, p. 87). El nivel alcanzado por la lucha de clases se verá acelerado en la medida en que la burguesía abandone sus obras 
de paz social y su política conservadora, porque, de esta manera, asumirá más cabalmente su papel de creadora de fuerzas productivas, incluyendo entre estas como la principal al proletariado mismo. En general, el autor señaló que mientras mayor sea la distancia entre las clases, mejor será el desarrollo del movimiento revolucionario. En opinión suya, la dinámica capitalista empuja al proletariado a la rebelión: «El capitalismo empuja al proletariado a la rebelión porque en la vida diaria, los patronos utilizan su fuerza en un sentido contrario al deseo de sus obreros» (Sorel, 1973, p. 87).

Sorel terminó su reflexión sobre la necesidad histórica de la violencia estableciendo que, cualitativamente, es distinto hablar del triunfo revolucionario en épocas de auge del capitalismo (análisis de Marx) que hacer un análisis en época de decadencia burguesa; ilustró su trabajo con los casos de la Revolución francesa, el cristianismo y las invasiones bárbaras. Analizó los casos anteriores a la luz del peligro que representa para el movimiento revolucionario triunfar en época de decadencia, puesto que el proletariado se vería absorbido y embrutecido. En este sentido, arremetió contra el socialismo parlamentario:

En muchas ocasiones, se ha expuesto el socialismo civilizado de nuestros doctores oficiales como salvaguardia de la civilización, yo creo que causaría el mismo efecto que produjo la instrucción clásica dada por la Iglesia a los reyes bárbaros: el proletariado sería corrompido y embrutecido como lo fueron los merovingios y la decadencia económica seria aún más cierta bajo la égida de esos presuntos civilizadores (Sorel, 1973, p. 94).

¿Cómo evitar dichos peligros? El autor respondió de modo directo:

Todo puede salvarse si, mediante la violencia logra el proletariado consolidar de nuevo la división de clases, y devolver a la burguesía algo de su energía, tal es la gran meta hacia la cual ha de ser dirigido todo el pensamiento de los hombres... La violencia proletaria ejercida como una pura y simple manifestación del sentimiento de lucha de clases, aparece así como algo muy serio y heroico, está al servicio de los intereses primordiales de la civilización, no será quizá el método más apropiado para obtener mejoras materiales inmediatas, pero puede salvar al mundo de la barbarie (Sorel, 1973, p. 95). 


\section{El papel revolucionario de la huelga general.}

El tema de la violencia proletaria aparece en el pensamiento soreliano siempre relacionado con el de la huelga general. La huelga general puede ser empleada como medio para distinguir el socialismo revolucionario de las doctrinas propias de los revolucionarios aficionados. Sorel enfocó su crítica contra los socialistas parlamentarios, para quienes la lucha de clases debe estar subordinada a una abstracta solidaridad. Frente al socialismo decadente de los parlamentaristas, levantó la bandera del sindicalismo revolucionario, al cual caracterizó del modo siguiente: «El sindicalismo revolucionario que, por el contrario, se afana porque nada quede indeciso. En el pensamiento se expresa honradamente, sin supercherías ni sobrentendidos; no se intenta diluir las doctrinas en un torrente de comentarios embrollados (Sorel, 1973, p. 123).

Con esta posición Sorel se enfrentó a quienes han pretendido vaciar de su contenido revolucionario al movimiento obrero, tal como sucedió con el movimiento de trabajadores ingleses, donde la idea de huelga general no caló lo suficiente, imponiéndose las tesis economicistas de las trade-uniones, que dieron pie a la creación de la llamada aristocracia obrera:

Que la huelga general no se haya popularizado entre los ingleses de hoy constituye un pobre argumento contra el alcance histórico de la idea, pues los ingleses se distinguen por la extraordinaria incomprensión de la lucha de clases. En su pensamiento predominan principios medievales; la corporación privilegiada o, cuando menos, protegida por las leyes, se les aparece como el ideal de la organización obrera (Sorel, 1973, p. 124).

Una vez desautorizado el modelo inglés de organización obrera, Sorel propuso como alternativa superar, por una parte, las tendencias que subestiman la huelga general en favor de la supresión del capitalismo a través de relatos históricos (utopía antigua) y, por otra parte, enfrentar el reto de pensar el porvenir. El mito, en tanto expresa las tendencias de un pueblo, tiene gran utilidad en la medida que estos «se ofrecen a la mente con la insistencia de instintos en todas las circunstancias de la vida, y que confieren un aspecto de plena realidad a unas esperanzas de acción próxima en las cuales se basa la reforma de la voluntad» (Sorel, 1973, p. 126). 
Ilustró Sorel su argumentación sobre el papel del mito con los casos del cristianismo primitivo, Lutero y el calvinismo. Dicho en otras palabras, lo significativo de un mito es su capacidad para movilizar a todo un pueblo.

Tomando como punto de partida las representaciones de quienes estaban auténticamente comprometidos con el movimiento revolucionario, se puede decir que:

La huelga general es el mito en el cual el socialismo entero está encerrado, es decir, una organización de imágenes capaces de evocar de manera instintiva todos los sentimientos que corresponden a las diversas manifestaciones de la guerra entablada por el socialismo contra la sociedad moderna (Sorel, 1973, p. 123).

Es así como Sorel le confirió máxima importancia al papel de la huelga general, como fuerza motriz del cambio revolucionario.

La huelga general fue el ariete con el cual se combatió, ardorosamente, a los llamados socialistas oficiales. La praxis del marxismo, para Sorel, pasó necesariamente por la huelga general. En su introducción a los principios generales sobre el marxismo abordó, en primer lugar, el tópico de la lucha de clases, y consideró que este debía ser el punto de partida del socialismo. Encontró nuestro autor que el ejemplo de la división del trabajo en las fábricas permite, con mayor claridad, entender la naturaleza irreductible del conflicto de clases expuesto por Marx. Pero la huelga general es, sin embargo, la que puede poner al desnudo la naturaleza del conflicto: «Ninguna explicación filosófica de los hechos observados en la práctica podría aportar tan viva luz como la perspectiva tan sencilla que la evocación de la huelga general nos pone ante los ojos» (Sorel, 1973, p. 135).

\section{La moralidad de la violencia}

La violencia es primordialmente moral. En el desarrollo de esta idea sorel expuso: a)- Su repudio a los prejuicios que se propagan contra la violencia. Prejuicios alimentados por las ideas de paz y dulzura; b)- su rechazo a que la violencia signifique un retorno a la barbarie; c)- una crítica a la sumisión que caracterizó a sus contemporáneos; y d)-su concepción de que 
la violencia que rebasa ciertos límites puede ser peligrosa para la moralidad. Para él, uno de los elementos que explica la aversión burguesa que sienten los socialistas parlamentarios por la violencia proviene de un proceso que se inició con la eliminación de castigos físicos en las escuelas y fábricas, así como con el abandono de la brutalidad que caracterizó a los gremios de artesanos, de lo cual se hace una extrapolación ideológica indebida. «Todos estiman que la desaparición de esas antiguas brutalidades es cosa excelente, resultaba demasiado fácil pasar esa opinión a la idea de que toda violencia es un mal» (Sorel, 1973, p. 199). Tal sentimiento o aversión a la violencia obedece más a las trasformaciones sufridas en el mundo criminal, que a principios ético-políticos. La ética del proletariado proviene de sus aspiraciones revolucionarias, ellas le infunden mayor fuerza y elevación.

En el discurso político soreliano encontramos, por lo tanto, que la violencia es el mayor valor al que deben aspirar los revolucionarios auténticos. Considero que la moralidad de la violencia revolucionaria, dado los alcances trasformadores que comporta, es el medio legítimo con que cuenta el proletariado para concretar su misión histórica. De esa necesidad histórica se deriva el significado, profundamente moral, que adquiere la violencia cuando es asumida por el sujeto revolucionario.

\section{Referencias}

Chevallier, J. (1967). Los grandes textos políticos. Madrid, España: Editorial Aguilar, sexta edición.

Gallardo, H. (1989). Actores y procesos políticos latinoamericanos. San José, Costa Rica: DEI. Guevara, E. (1977a). Obras (volúmenes del I al II). La Habana, Cuba: Editorial Casa de las Américas.

Guevara, E. (1977b). Escritos y discursos. La Habana, Cuba: Editorial de Ciencias Sociales.

Guevara, E. (1977c). El socialismo y el hombre nuevo. México: Editores México.

Hobbes, T( 1994). Leviatán. México; Ediciones Gernika, S.A

Lenin, V. (1979). El Estado y la revolución. Moscú, Rusia: Editorial Progreso.

Marx, K. y Engels, F. (1978a). Manifiesto del Partido Comunista. Moscú, Rusia: Editorial Progreso.

Marx, K y Engels, F (1978b). Obras escogidas. Moscú, Rusia: Editorial Progreso

Sorel, G. (1973). Reflexiones sobre la violencia. Madrid, España: Editorial La Pléyade. 